Luis Fernando Marín ARDila

Profesor Universidad Pedagógica Nacional

\title{
LA NOCIÓN DE CRISIS DE PARADIGMA EN LA EDUCACIÓN
}

La noción de paradigma se ha convertido en una expresión de uso frecuente en los medios académicos y universitarios. Indica este uso, de un lado, el conocimiento más o menos familiar que se tiene de un vocabulario que se hizo famoso en la historia de la ciencia y la filosofía de la ciencia a partir del impacto que produjo la publicación y la ulterior discusión del famoso libro de Thomas S. Kuhn: La Estructura de las revoluciones científicas, en $1962^{1} ; y$, de otra parte, indica el que las instituciones se ven ocupadas de cuando en cuando por nociones que circulan cual palabras fetiches, palabras mágicas mediante las cuales se dice mucho y se dice poco.

Este articulo pretende, en primer lugar, acercarse a una delimitación del término en mención, para lo cual tomaremos como hilo conductor la obra de Kuhn y la discusión que en torno a la misma se ha generado, así como también el trabajo de Edgar Morin, el sociólogo francés que ha incursionado en el debate en el cuarto tomo de su obra central EI Método². En segundo lugar, mi objetivo es el

\footnotetext{
${ }^{1}$ Kuhn, Thomas, S. La Estructura de las Revoluciones Científicas, F.C.E., México, 1986.

${ }^{2}$ Morin, Édgar. El Método, las ideas, Cátedra, Madrid, 1992.
}

de acotar los usos que dicho término puedan prestarnos en nuestra comunidad académica.

\section{EL TÉRMINO}

Si leemos en el diccionario, paradigma es: modelo, ejemplo. El filósofo norteamericano lo define de la siguiente manera: "Un paradigma es lo que los miembros de una comunidad científica comparten, y, recíprocamente, una comunidad científica consiste en hombres que comparten un paradigma" $\left(\right.$ Kuhn, 1962) ${ }^{3}$. La definición escueta no sólo aparenta circularidad sino inocuidad. ¿Qué nos dice dicha definición?: nos dice que un paradigma es un conjunto de valores y saberes compartidos colectivamente, es decir, usados, implícita o explícitamente por una comunidad. Compartidos significa también covalidados tácita o temáticamente. Estas aclaraciones extensivas de la definición nos pueden sacar de la circularidad y la inocuidad para sumergirnos en la vaguedad, en efecto, podemos decir que un paradigma es:

\footnotetext{
${ }^{3}$ Kuhn, T. S. Ibid., págs. 33 y ss.
} 
1. Algo que está constituido por los descubrimientos científicos universalmente reconocidos que, durante cierto tiempo, proporcionan a un grupo de investigadores problemas tipo y soluciones tipo. Y,

2. Un paradigma es el conjunto de las creencias, valores reconocidos y técnicas que son comunes a los miembros de un grupo dado.

Atendiendo a esta delimitación en Kuhn, podemos decir que la vaguedad se da cuando la definición 2, introduce el concepto de la adhesión de un grupo a una visión de mundo; la definición 1 corresponde a la primera edición de la Estructura de las Revoluciones Científicas; la definición 2 a los ulteriores ediciones. La vaguedad alude, entonces, a que compartir un paradigma, en la definición 2 , es la de poseer una representación colectiva o vivir en una cosmovisión o ideología.

La generalidad de esta lectura de la noción de paradigma es no solamente visible sino además es la que se da en nuestro medio universitario cuando se afirma que formamos parte de la "cultura judeocristiana" o de la "cultura Occidental" o de la "modernidad" o del "determinismo". Sin desmeritar esta perspectiva generalizante de la noción, mencionemos algunas de las consecuencias que Kuhn supo expresar con respecto a esto.

Atendiendo a lo anterior, digamos que, las teorías científicas se destacan no solamente por las leyes y las aplicaciones nos dice Kuhn, además son cruciales aspectos tales como las comunidades científicas, las convicciones y creencias y el período histórico en que aparecen las teorías. Lo cual significa que la ciencia no es sólo lo que formula leyes, sino lo que comparte en términos de lenguaje, de visión, de socialización y de valoración una comunidad. De otra parte, la noción de paradigma deja entrever las consideraciones más importantes de Kuhn sobre la historia de la ciencia, afirmando que la ciencia no es una sucesión continua y acumulativa del saber, sino que responde más a la característica de una realidad de dos grandes y diferenciados momentos a saber: la ciencia normal y la ciencia extraordinaria o revolucionaria. Los momentos o períodos normales se caracterizan por la preponderancia o dominio de unas formas y métodos de investigación bien establecidos, casi rutinarios, condicionantes tanto de los problemas a tratar como la manera de solucionarlos. En este período no sólo se constituye el paradigma sino que también al interior de éste se produce una acumulación de saber, de conocimiento. En contraste con esto, los momentos extraordinarios se dan cuando ciertas experiencias, ciertos fenómenos no se asimilan a esas rutinas de la normalidad y se entra en un período de crisis, se desconfía entonces de los procedimientos normales y se postulan teorías alternativas, que permitan resolver bajo otra visión las anomalías detectadas. Es el momento in statu nascendi de un nuevo paradigma, es el momento en que nos está persuadiendo una nueva forma de abordar la problemática en cuestión y/o las modalidades de su tratamien- to; la siguiente etapa será la de la conversión. Esta nueva forma de ver y de hablar con relación a la anterior es inconmensurable, se pueden establecer aspectos comparativos, mas no decir que entre los problemas y las soluciones del anterior paradigma y el nuevo existe una continuidad y una acumulación de fórmulas. V. gr., no hay traducción posible entre la mecánica de Newton y la física de Aristóteles. Lo cual significa que no es que los hechos de la experiencia sean los mismos bajo otra interpretación, es decir, que sean neutrales a los paradigmas que los cobijan. Como dice el profesor Germán Guerrero: "Los hechos de la experiencia no pueden desempeñar una función neutral en los cambios de paradigma puesto que el hecho mismo está determinado por el paradigma. Científicos que pertenecen a paradigmas diferentes ante un mismo conjunto de estímulos, que se pueden considerar idénticos para ambos, tienen sensaciones diferentes. Esta diferencia en la percepción se origina porque lo que se ve depende tanto del mundo como de la reeducación visual y conceptual previa" (Guerrero, 1997) ${ }^{4}$. Es lo que podríamos llamar un cambio de Gestalt, estructura perceptiva o aparato generador de imágenes como lo dice Konrad Lorenz ${ }^{5}$. Kuhn alude aquí a la experiencia del pato-conejo: dos hombres sometidos a la misma estimulación visual tienen impresiones diferentes, mientras uno ve un conejo, el otro ve un pato.

\footnotetext{
${ }^{4}$ Varios, Thomas Kuhn, Univalle, Santiago de Cali, mayo de 1997.

${ }^{5}$ Lorenz, Konrad. La otra cara del espejo, Plaza y Janés, Barcelona, 1974.
} 
Puede suceder el caso de los lentes inversores; los objetos que caen en el campo visual del hombre que tiene los lentes inversores al principio se ven invertidos, pero una vez se acostumbra a verlos de este modo se reeduca la vista y los va a ver de esta nueva forma sin tener los lentes. En conclusión un cambio de paradigma trae consigo un cambio de la percepción del mundo.

\section{EL TÉRMINO Y SUS CARACTERÍSTICAS}

Edgar Morin propone la siguiente definición: "un paradigma contiene, para cualquier discurso que se efectúe bajo su imperio, los conceptos fundamentales o las categorías rectoras de inteligibilidad al mismo tiempo que el tipo de relaciones lógicas de atracción/repulsión (conjunción, disyunción, implicación u otras) entre estos conceptos o categorías". (Morin, 1991)

Con relación a esta definición se destaca el hecho de que Morin insiste en los paradigmas como profundas inscripciones o sellos -imprinting-que los individuos y los grupos tienen culturalmente. Esas inscripciones y sellos son semánticas, lógicas e ideo-lógicas. Semánticas porque el paradigma determina inteligibilidad y sentido, es decir, el paradigma nos hace actuar, pensar y hablar con comprensibilidad y coherencia; asegura nuestro fondo básico de creencias. Lógicas, por cuanto que el paradigma determina las operaciones lógicas rec-

${ }^{6}$ Morin, Édgar. Método, las ideas, págs. 216 y ss.

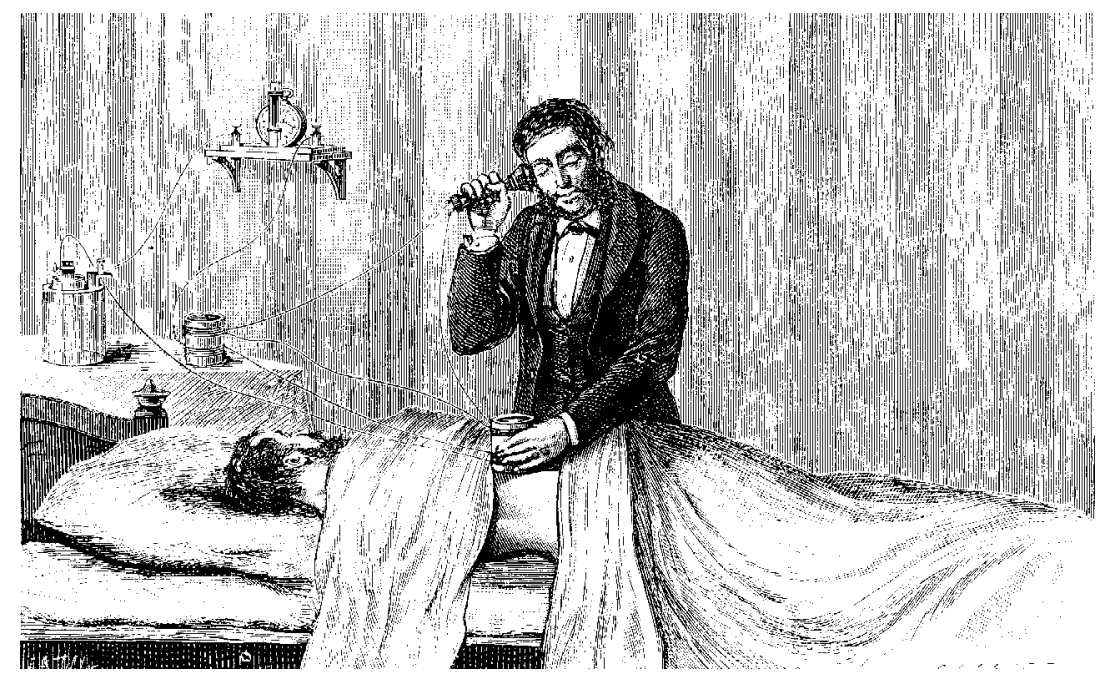

toras, es decir, el paradigma define reglas de juego, jugadas válidas o no. Ideo-lógicas, por cuanto que el paradigma es una matriz de ordenación de ideas. El paradigma es generativo y organizacional: "Tomemos un ejemplo: existen dos paradigmas dominantes en lo concerniente a la relación hombre/naturaleza. El primero incluye lo humano en lo natural, y cualquier discurso que obedezca a este paradigma hace del hombre un ser natural y reconoce la "naturaleza humana" El segundo paradigma prescribe la disyunción entre estos dos términos y determina lo que de específico hay en el hombre por exclusión de la idea de naturaleza. Estos dos paradigmas opuestos tienen en común el que uno y otro obedecen a un paradigma todavía más profundo, que es el paradigma de simplificación, el cual, ante cualquier complejidad conceptual, prescribe o bien la reducción (aquí, entre lo humano y lo natural), lo que impide concebir la unidualidad (natural y cultural, cerebral y psíquica) de la realidad humana, e impide igualmente concebir la relación a la vez de implicación y separación entre el hombre y la naturaleza. Hace falta un paradigma complejo dialógico de implicación/disyunción/conjunción que permita una concepción tal" (Morin, 1991) 7 .

En conclusión para Morin la naturaleza de un paradigma puede ser definida como la de promoción/selección de categorías rectoras o conceptos fundamentales de inteligibilidad y la determinación de operaciones lógicas rectoras. Lo cual significa que el paradigma es inconsciente, irriga al pensamiento consciente, lo controla y, en ese sentido, es también supraconsciente (Morin, 1991) $)^{8}$.

1. El paradigma no lo podemos invalidar, falsar, acabar, destruir. No es posible invalidarlo ni verificarlo empíricamente,

\footnotetext{
7 lbíd., págs. 226 y ss.

${ }^{8}$ Ibíd., págs. 220 y ss.
}

\section{CARACTERÍSTICAS DEL PARADIGMA}


esto lo acerca a la noción de ideología. El paradigma es un marco interpretativo que está eximido de la alternativa falso o verdadero. No podemos decir que los marcos interpretativos causalistas, mecanicistas y deterministas sean a este respecto errores científicos. El paradigma pierde vigencia paulatina e imperceptiblemente. Por ejemplo, considerar a los medios de comunicación de masas como guiados por la lógica de la manipulación es un paradigma que no ha sido vencido por una evidencia empírica que diga lo contrario; lo que ha ocurrido es que otro eje interpretativo -la perspectiva de las teorías de la recepción-, entre tanto, ha ganado mayor uso y poder explicativo y, por consiguiente, el modelo manipulativo ha palidecido.

2. El paradigma es exclusivo y excluyente. Datos, enunciados, ideas, que no sean conformes a su marco de referencia no los reconoce. Por ejemplo, si afirmamos con el paradigma de simplificación que: "una cosa es una cosa y otra cosa es otra cosa", entonces excluimos la posibilidad de una afirmación compleja del tipo "el todo está en la parte y en la parte está el todo".

\section{El paradigma nos enceguece} para lo que excluye como si no existiese. El paradigma es inconsciente, es supraconsciente, es decir, el paradigma se internaliza y como férrea anteojera no permite ver otras posibilidades. Ejemplos: en la Edad Media :"la tierra es plana", o en el siglo XIX: "el hombre o la humanidad progresan", etc.

4. El paradigma es invisible. Es un organizador invisible. Siempre es virtual, el paradigma nunca es formulado en tanto que tal, no existe más

6. El paradigma crea la sensación de lo que es real. (Ejemplo determinismo versus probabilismo). Lo real es lo determinable y las aleatoriedades y casualidades son irreales 0 desechables.

7. Como es invisible, el paradigma es invulnerable. Esta indestructibilidad es relativa, el talón de Aquiles de los paradigmas tiene que ver con los individuos, su creatividad, imaginación y los caldos de cultivo e interacciones entre distintas culturas. La vida de los paradigmas ya lo dijimos se puede extinguir paulatina y muchas veces, imperceptiblemente.

plos. Nuestro marco perceptivo, nuestro marco mental, de pensamiento, de actuación y de lenguaje siempre se da como un trasfondo inadvertido, como una red de supuestos, como una red de valores y de valoraciones intangibles $y$, sin embargo, insidiosamente presentes. Francis $\mathrm{Ba}-$ con en el siglo XVII los describió como los ídolos de la tribu (propios de la sociedad), de
8. Los paradigmas son inconmensurables entre sí. La vida de la ciencia y de las teorías científicas no obedece a un efecto lineal, acumulativo y progresivo. Los paradigmas en los cuales se alojan y se producen las ciencias son entre sí intraducibles, no existe la posibilidad de un lengua- 
je meta-paradigmático que puede medir y conmensurar un paradigma con relación a otro.

\section{Un gran paradigma determi-} na una visión de mundo. Sólo el cambio de una época, un gran cisma religioso, una gran revolución social, un estrepitoso triunfo o una igualmente contundente derrota (ejemplo caída del muro de Berlín) son la ocasión para cerciorarnos de como estaba implantada hondamente una creencia, un modo particular de vivir y actuar conforme a unos valores, a unos pensamientos, a unas verdades.

\section{LA CRISIS DE LOS PARADIGMAS EN LA ACTUALIDAD}

Ya nos ubiquemos en el esquema de la historia de la ciencia de Thomas S. Kuhn, para el cual la situación presente se describiría como la de un período de ciencia revolucionaria o crisis del paradigma tradicional, o nos ubiquemos en la perspectiva de Edgar Morin, para el que el período es, ciertamente, transformativo de un paradigma simplificador, racionalizador, abstracto, disyunto y reductor por un paradigma de la complejidad y la incertidumbre; por cualquiera de los lados que se mire, repito, la universidad, la academia, la producción teórica, el debate intelectual están atravesando por una profunda crisis desde hace unos buenos lustros; ahora bien, esa crisis también se ha generado en y con la sociedad y la cultura en general. Aproximémonos a una posible descripción de los estratos o capas que el cambio paradigmático va marcando:

1. Primera capa o estrato de transformación: Sucede en el "gran paradigma de occidente" y hace alusión a la crisis de la noción de cultura superior y a la realidad que refiere la existencia de los dualismos de Sujeto/Objeto; Alma/Cuerpo; Espíritu/Materia; Cualidad/ Cantidad; Finalidad/Causalidad; Sentimiento/Razón; Libertad/Determinismo; Existencia/Esencia. El paradigma no sólo determina los conceptos fundamentales de inteligibilidad sino además la lógica de su relación. De tal suerte que para occidente el ser o la realidad es de un lado sujeto y de otro, completamente diferente, objeto; de un lado sentimiento y de otro la razón; donde está el sentimiento está ausente la razón y viceversa, etc. Un valor es positivo, el otro negativo. Estas mutuas exclusiones y separaciones están cuestionadas desde todos los ángulos: desde la microfísica, las ciencias sociales y la vida y comprensión cultural de los hombres de la actualidad e hijos de occidente. Una cultura que considere al sujeto como fuente de perturbaciones y de errores, que estigmatice el cuerpo como la envoltura de algo sagrado llamado alma, que considere, igualmente, que el caos, el azar y lo probable son casos fortuitos y accidentes contingentes que no interfieren en la generación de leyes y cálculos rigurosos, está por fuera de una experiencia que cada vez es más valorada, a saber la lec- tura e inteligibilidad de nuestro conocimiento, nuestra cultura y nuestro ser por lo que sucede en lo marginal, en lo periférico y eventual.

2. La ciencia y el conocimiento durante mucho tiempo predicaron su esencia o característica definitoria como la del funcionamiento que sustituye lo visible complicado por lo invisible simple. De tal suerte que el conocimiento, la ciencia y la educación tendrían como regla de oro el ir de lo complejo a lo simple. El conocimiento y la ciencia explicarían la realidad mediante el análisis, es decir, mediante la descomposición del todo en sus partes. La realidad se entiende de este modo como un agregado de partes que la ciencia determina. Aquí el paradigma es reductor y abstrae. El sentido del conocimiento accede hoy a niveles donde la lógica dilemática, binaria y abstracta es sustituida por un conocimiento no sólo complejo por su sensibilidad a la totalidad y sus múltiples variables, sino porque la complejidad se nutre del contexto en el que el conocimiento actúa y vive; porque, además, el conocimiento es y se mueve en la incertidumbre; porque el conocimiento es consciente de su parcialidad y de su radical inmersión en contextos sociales, culturales y subjetivos.

3. El paradigma tradicional en nuestra cultura sigue siendo muy fuerte, ya que muchos actores sociales todavía lo usan y lo vehiculan. Ese paradigma tradicional lo resumo 
en la existencia de tres conceptos claves que en su interacción generan una visión del mundo o gran ideología. Los conceptos en mención son los siguientes: El conocimiento como representación; el lenguaje como instrumento; la educación como transmisión.

\section{EL CONOCIMIENTO COMO REPRESENTACIÓN}

El conocimiento como re-presentación: El paradigma que estamos describiendo posee como afirmación subyacente que la ciencia busca o descubre la verdad; verdad que se expresa en la adecuación de unas proposiciones lingüísticas a la realidad. También subyace el valor de que el conocimiento es una dimensión representacional; es decir, que el conocimiento es por esencia teórico, contemplativo y distanciador frente a la vida cotidiana. El conocimiento así entendido cumpliría por definición funciones cognoscitivas que distancian al sujeto (cognoscente) de los objetos y de los contextos en que habla y vive. Esta deriva contemplativa no se dirige a una ascética espiritual como en la Edad Media, sino a una educación memorística y del control social vía autoritarismo profesoral.

De este modo entendido, una educación filosófica contemporánea, allende la representación, enfatizará las características pragmáticas y adaptativas del conocimiento. El conocimiento se percibe inmerso hoy en un marco de referencia en el que se coloca más como un hacer, como un acto, que como una serie de etapas mentales progresivas para acceder al ser. Eso significa que el conocimiento (esta tendencia es visible desde el siglo XVII, inicio de la Modernidad) deja de ser del dominio exclusivo de los intelectuales y se convierte en el medio común por el que las sociedades (precisamente llamadas sociedades del conocimiento) se organizan, se ven sujetas al cambio y se adaptan. En las que la educación subordina los procesos de enseñanza por la centralidad que adquieren los

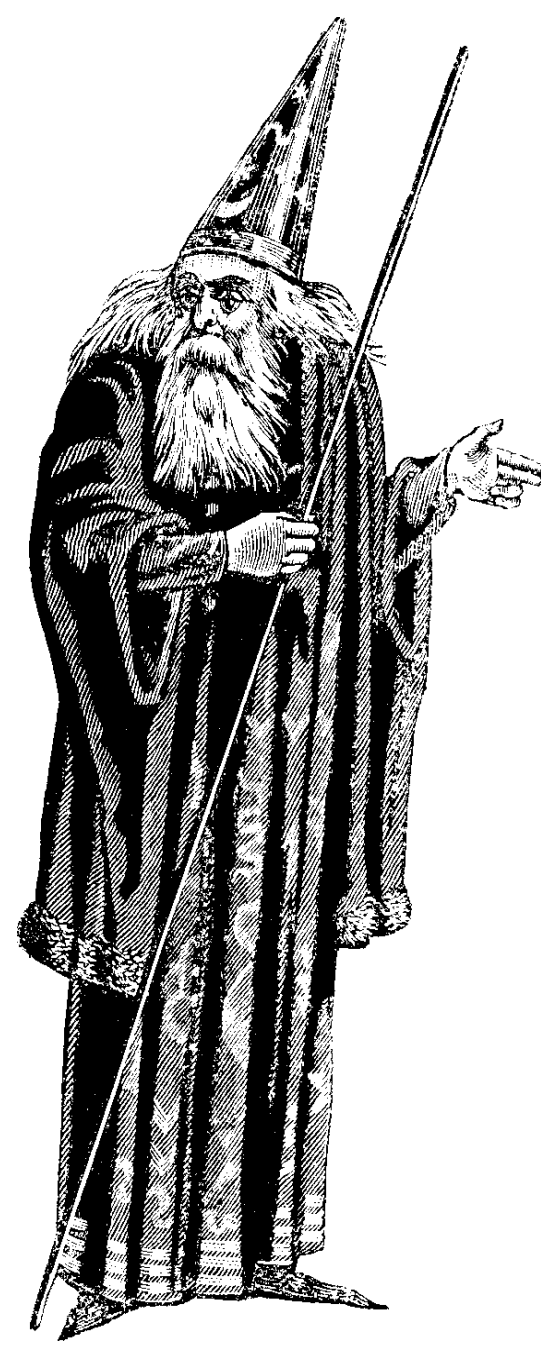

procesos de aprendizaje. Esto rige igual que para las sociedades, para los individuos.

En las sociedades del pasado, el conocimiento se consideró como un lujo de castas, clases o capas privilegiadas que lo cultivaban como un signo de distinción y de poder. Mediante el conocimiento cultivaban la parte más noble y digna de su humanidad y de su aristocrático ser. El conocimiento obedecía a la realización de la mejor forma de vivir o vida buena, que era la contemplativa o teórica; colocaba al sujeto del conocimiento en un estado de identificación con la totalidad del ser o de la realidad, que él mismo descifraba cuando sus partes inferiores quedaban relativizadas por la ascensión espiritual que el conocimiento lograba a partes superiores del hombre.

Esa mimesis o identificación del espectador con el espectáculo es lo que los griegos llamaron teoría. Ese designio contemplativo estaba, entonces, acompañado de una inclinación o resorte permanente del conocimiento y de la investigación que denominamos, interés teórico. Este interés sin estar del todo ausente en la actualidad, se ve seriamente competido y, superado muchas veces, por otra valoración del mismo, por otro uso y otro significado. A la base de nuestra cultura y de nuestras sociedades, el conocimiento y la investigación se ven configurados por un interés práctico $\mathbf{u}$ operativo. La pertinencia de dicho interés tiene que ver más que con el desciframiento del mundo y su observación admirativa, con su transformación, 
constitución, manipulación y adaptación.

Entonces, el paradigma que tiende a constituirse en dominante tiene como algunas de sus características el ser uno que opta por la cotidianidad, la contextualización, el cuerpo, la pluralidad, la complejidad, la incertidumbre, la inseparabilidad de conocimiento y vida; además dialógico, sensible a lo eventual, policéntrico y valorizador de lo que por el paradigma anterior se considero accesorio, insubstancial y caótico. El conocimiento se percibe inmerso hoy en un marco de referencia donde se coloca más como un hacer que como un medio para acceder al ser. El conocimiento deja de ser dominio exclusivo de los intelectuales y se convierte en el medio común por el que las sociedades (llamadas sociedades del conocimiento) se organizan, se ven sujetas al cambio y se adaptan.

\section{EL PARADIGMA CONCIBE AL LENGUAJE COMO INSTRUMENTO}

El lenguaje como medio: Varios son los aspectos que pueden describir este componente. Me voy a limitar a señalar el que para este paradigma en crisis, el significado no se constituye en la interacción -en el uso o comunicación-, sino que viene perfectamente preformado -a priori-. Tanto las visiones formales y sintactistas del lenguaje como las racionalistas, consideran el significado lingüístico separado del contexto de comunicación, de tal suerte que la comunicación, en cada evento educativo o transmisivo, sólo es una movilización o actualización de significados preconcebidos.

Otro aspecto resaltable de este instrumentalismo es que durante mucho tiempo se privilegio el contenido de las locuciones y no sus modalidades: se privilegió el qué se dice y no el cómo se dice. La estructura locucionaria del lenguaje se subrayó frente a dos estructuras, igualmente presentes en las realizaciones del lenguaje. De un lado la estructura modal ilocucionario (que describe la pretensión o intención del hablante y la realización con el lenguaje de un acto, es decir, la ejecución de una acción social como en el saludo, por ejemplo) y la estructura modal o perlocucionaria (que describe los actos o comportamientos producidos con y por la enunciación en los sujetos a los cuales se dirige el acto de habla). Este énfasis de lo locucionario se da por cuanto que subyace la concepción del lenguaje como el vehículo o fenómeno comunicante que liga los polos emisor y receptor.

Ese desconocimiento de las estructuras pragmáticas y modales, es el que conduce a que el lenguaje sea un fenómeno que hace posible que lo que pensamos, concebimos y creamos en privado, en nuestra mente, haga su aparición en público. El lenguaje es un sirviente del pensamiento y de la intención comunicante. Esto significa que es como una membrana pura, absolutamente transparente que debe ser lavada de ambigüedades y polisemias para que traduzca fielmente a su amo y señor. El escaso papel del lenguaje de esta consideración, viene dado por una concepción instrumental

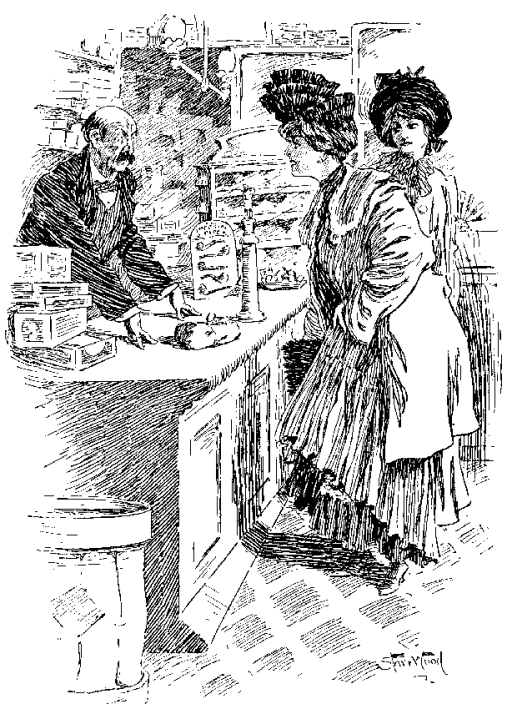

para la cual el medio es secundario frente a la intención comunicativa del pensamiento.

Frente a esta mentalidad incorporada en nuestras prácticas educativas habría que señalar el olvido de la dimensión del ser del lenguaje, dimensión que tiene un valor por sí misma, al constituirse en una realidad no neutra de nuestros pensamientos y sentimientos; el lenguaje es una forma de vida, es una realidad densa que conserva la memoria, el sentido y los significados más estimados de una colectividad humana. Ese lenguaje como forma de vida resalta la unidad fundamental entre él, el pensamiento y el mundo. Recordemos que Wittgenstein, el filósofo vienés más sobresaliente del giro lingüístico del pensamiento occidental, subrayó insistentemente como los juegos del lenguaje son una unión indisoluble entre las normas lingüísticas, las situaciones objetivas y las formas de vida. Además, esta unión entre límites del lenguaje, límites del mundo y límites del pensamien- 
to, conlleva a afirmaciones tales como que el acuerdo en los significados es un acuerdo igualmente, en los juicios. Compartir una cultura, unos sentidos del ser, del actuar y del sentir, conlleva el compartir también unas valoraciones o juicios de valor sobre lo verdadero, lo bueno, lo correcto, lo importante, lo digno y lo que no lo es. Esto lo expresó Wittgenstein con la afirmación del lenguaje como una dimensión realizativa y no meramente enunciativa o designativa.

\section{EL PARADIGMA CONCIBE A LA EDUCACIÓN COMO TRANSMISIÓN}

La educación como transmisión: En el paradigma tradicional la educación es un mecánico desplazamiento, siendo el conocimiento una copia o adecuación a la realidad y el lenguaje un simple medio de comunicación. La educación es la ejecución, obtenida después de la búsqueda y hallazgo del conocimiento, de los medios más expeditos y eficaces para dar, entregar o transportar el saber de un sujeto que lo detenta a unos sujetos vacíos o carentes de tal. En la práctica educativa existe un sujeto despojado, puro, pura potencialidad maleable y esculpible por el sujeto enseñante. Ese sujeto en estado de pura competencia, no es por supuesto el otro, sino el continente vacío educable de pies a cabeza, cien por cien. Este sujeto no es el de la interacción en una comunidad de lenguaje, mundo y pensamiento. No es el integrante de mi forma de vida $y$ cultura sino un sujeto abstracto, separado del contexto y objetivable por una mirada repre- sentacional y distanciadora. En conclusión si el conocimiento es una copia o adecuación a la realidad y el lenguaje un simple medio de comunicación, la educación consiste en buscar los medios más eficaces para trasmitir el saber de un sujeto que lo detenta a unos sujetos carentes o vacíos de tal, cuya actividad se limita a dejarse enseñar.

Desde esta característica el paradigma educativo en crisis y, no obstante persistente, es curricularizante. No se entiende sino desde la visión de un agregado de temáticas, de asignaturas o materias. La transversalidad, la flexibilización y la inter y transdisciplinariedad no penetran la férrea costra de la sumatoria de información. Esta educación por contenidos, como se sabe, se pretende superar invocando los construccionismos y los discursos sobre las competencias. Frente a estas alternativas -problemáticas y muy cuestionadasen este articulo se prefiere señalar como pertinente el desafío de complejidad ${ }^{9}$ que involucra dimensiones éticas, políticas y conceptuales sobre la educación actual. Este desafío de complejidad tiene el atractivo de entender la educación desde horizontes no reduccionistas y no abstractos.

\footnotetext{
${ }^{9}$ Morin, Édgar. Los siete saberes necesarios para la educación del futuro, UnescoMEN, 2000.
}

\section{BIBLIOGRAFÍA}

Kunn, Thomas, S. La Estructura de las Revoluciones Científicas. México. FCE, 1986.

Morin, Édgar. El método, las ideas. Madrid. Cátedra, 1992.

KuHN, T. S. Ibid., págs. 33 y ss.

VARIOS, Thomas Kuhn. Santiago de Cali. Univalle, mayo de 1997.

LoREnZ, Konrad. La otra cara del espejo. Plaza y Janés.

MoRIn, Édgar. Método, las ideas, págs. 216 y ss.

MoRIN, Édgar. Los siete saberes necesarios para la educación del futuro. Unesco-MEN, 2000. 